MaPan : Jurnal Matematika dan Pembelajaran

p-ISSN: 2354-6883 ; e-ISSN: 2581-172X

Volume 6, No 2, December 2018 (187-198)

DOI: https://doi.org/10.24252/mapan.2018v6n5

\title{
PENERAPAN MODEL PEMBELAJARAN KOOPERATIF PADA MATA KULIAH PROGRAM LINEAR MELALUI LESSON STUDY
}

\author{
Jumarniati1), Desak Made Ristia Kartika ${ }^{2}$, M. Rusli Baharuddin ${ }^{3)}$ \\ 1,2,3Universitas Cokroaminoto Palopo \\ 1,2,3 Jalan Latammacelling No. 19 Kota Palopo \\ E-mail: jumarniati@ uncp.ac.id $\left.{ }^{1}\right)$, desakmaderistia@ uncp.ac.id²),
}

Submitted: 12-09-2018, Revised: 29-09-2018, Accepted: 08-12-2018

\begin{abstract}
Abstrak:
Penelitian ini bertujuan untuk memperbaiki proses dan kualitas pembelajaran mata kuliah program linear mahasiswa semester IV Program Studi Pendidikan Matematika melalui Lesson Study. Penelitian ini merupakan penelitian deskriptif, dengan tujuan untuk mendeskripsikan hasil observasi/pengamatan akivitas mahasiswa dan dosen. Kegiatan Lesson Study dilakukan sebanyak dua kali open class, masing-masing open class terdiri dari tiga tahap kegiatan yaitu: perencanaan (plan), pelaksanaan, (do), dan refleksi (see). Pembelajaran dilakukan melalui penerapan model kooperatif. Hasil yang diperoleh dalam penelitian ini adalah: meningkatkan aktivitas mahasiswa dengan penerapan model kooperatif pada mata kuliah program linear, meningkatkan pemahaman mahasiswa dalam mengerjakan masalah maksimasi dengan metode simpleks, interaksi antar mahasiswa dalam pembelajaran meningkat. Berdasarkan hasil di atas dapat disimpulkan bahwa model pembelajaran kooperatif pada mata kuliah program linear dalam kegiatan lesson study dapat meperbaiki proses dan kualitas pembelajaran.
\end{abstract}

Kata Kunci: Pembelajaran Kooperatif, Lesson Study, Program Linear

\section{THE IMPLEMENTATION OF COOPERATIVE LEARNING MODEL IN LINEAR PROGRAM SUBJECT THROUGH LESSON STUDY}

\begin{abstract}
:
The research aims to improve the process and quality of learning linear program at the fourth semester students of the Mathematics Education Study Program through Lesson Study activities. This research is descriptive research to describe the observation results of the students and lecturers activities. Lesson Study activities were conducted in two times open classes, each open class consisted of three activity phases, namely: planning (plan), implementation (do), and reflection (see). Learning was conducted through implementation of cooperative learning models. Based on the findings, it is recognized that the lesson study activities improve the students' activities through the implementation of cooperative model in the linear program subject, improve students' understanding in maximizing problems with the simple method, and improve the interaction among the students. Based on those findings, it can be concluded that the cooperative learning model in the linear program subject through lesson study activities can improve the process and quality of learning.
\end{abstract}

Keywords: Cooperative Learning, Lesson Study, Linear Program 
How to Cite: Jumarniati, Kartika, D. M. R., \& Baharuddin, M. R. (2018). Penerapan Model Pembelajaran Kooperatif pada Mata Kuliah Program Linear melalui Lesson Study. MaPan : Jurnal Matematika dan Pembelajaran, 6(2), 187-198.

atematika merupakan pelajaran yang melatih logika untuk
menyelesaikan masalah. Dalam belajar matematika, keaktifan
mahasiswa sangat dibutuhkan untuk melatih kemampuannya dalam menyelesaikan masalah. Program linear merupakan salah satu mata kuliah pada program studi pendidikan matematika yang menuntut mahasiswa aktif dalam menyelesaikan permasalahan-permasalahan yang berkaitan dengan pengoptimalan suatu model matematika. Pada pembelajaran program linear sebagian besar mahasiswa sulit dalam membuat model matematika dari suatu masalah, sedangkan dalam menyelesaikan masalah program linear sangat penting untuk mengetahui model matematikanya. Selain itu mahasiswa juga kurang aktif dalam pembelajaran dikarenakan kurang memahami materi, tidak berinisiatif untuk bertanya kepada dosen maupun temannya. Hal ini didasari oleh pengamatan dosen pengampu mata kuliah di kelas. Masalahmasalah tersebut bisa diatasi dengan penerapan model pembelajaran kooperatif dalam kegiatan lesson study. Penerapan model pembelajaran kooperatif dalam kegitatan lesson study membuat siswa bekerjasama dalam kelompok yang saling membantu untuk menyelesaikan suatu masalah, sehingga aktivitas mahasiswa dapat meningkat. Selain itu dosen juga dapat memperbaiki kualitas pembelajarannya dengan adanya bantuan dari dosen lain dalam hal perencanaan, pelaksanaan, dan refleksi.

Pembelajaran kooperatif mengacu pada model pengajaran dimana siswa bekerja sama dalam kelompok yang saling membantu untuk menyelesaikan atau memecahkan suatu masalah. Model pembelajaran kooperatif menekankan pengelompokan siswa yang heterogen. Salah satu prinsip dasar dari pembelajaran kooperatif adalah tujuan-tujuan kooperatif menciptakan normanorma kelompok yang mendukung pencapaian tinggi dalam prestasi belajar (Slavin, 2005).

Menurut Ibrahim (2005), unsur-unsur dasar pembelajaran kooperatif adalah sebagai berikut: (1) mahasiswa dalam kelompoknya harus beranggapan bahwa mereka sehidup sepenanggungan bersama, (2) mahasiswa bertanggung jawab atas segala sesuatu di dalam kelompoknya, seperti milik mereka sendiri, (3) mahasiswa haruslah melihat bahwa semua anggota di dalam kelompoknya 
memiliki tujuan yang sama, (4) mahasiswa haruslah membagi tugas dan tanggung jawab yang sama di antara anggota kelompoknya, (5) mahasiswa akan dikenakan evaluasi atau diberikan hadiah/penghargaan yang juga akan dikenakan untuk semua anggota kelompok, (6) mahasiswa berbagi kepemimpinan dan mereka membutuhkan keterampilan untuk belajar bersama selama proses belajarnya, (7) mahasiswa akan diminta mempertanggungjawabkan secara individual materi yang ditangani dalam kelompok kooperatif.

Lesson study pertama kali dikembangkan di Jepang yang dilaksanakan sebagai program pengembangan profesionalisme guru. Lesson study dipercaya berhasil dalam meningkatkan praktik pembelajaran. Lesson study pada awalnya dimulai dengan pengkajian kurikulum yang berfokus pada pengajaran matematika bagi guru-guru di Jepang untuk menguji keefektifan pengajarannya dalam rangka meningkatkan hasil pembelajaran. Kajian tersebut didasarkan pada kurikulum matematika di U.S. yang dirancang berbasis temuan-temuan penelitian unggul. Kajian tersebut melahirkan suatu perubahan paradigma tentang materi kurikulum dari "memanjakan" menuju pada "pemberdayaan" potensi siswa (Purwati \& Supandi, 2011).

Lewis (2002) menyatakan "lesson study is a cycle in which teachers work together to consider their long-term goals for students, bring those goals to life in actual "research lessons", and collaboratively observe, discuss, and refine the lessons"

Lesson Study bukan suatu metode pembelajaran atau suatu strategi pembelajaran, tetapi dalam kegiatan Lesson Study dapat memilih dan menerapkan berbagai metode/strategi pembelajaran yang sesuai dengan situasi, kondisi, dan permasalahan yang dihadapi pendidik (Suryaningtyas, Suprapti, Solikin, \& Shoffa, 2014). Stigler \& Hiebert (Tadanugi, 2015) menyatakan Lesson study digunakan untuk meningkatkan pengajaran di kelas. Didasarkan pada jangka waktu yang panjang, model perbaikan yang terus menerus, berfokus pada pembelajaran siswa, berfokus pada peningkatan langsung dalam mengajar, dan bersifat kolaboratif. Tahapan Lesson study menurut Saito (Tadanugi, 2015) adalah plan (perencanaan), do (pelaksanaan) dan see (refleksi). Berdasarkan beberapa penjelasan tentang lesson study dapat disimpulkan bahwa kegiatan lesson study merupakan kegiatan yang dapat dilakukan secara kolaboratif untuk memberikan kesempatan kepada guru/dosen dalam meningkatkan proses dan kualitas pembelajaran. 


\section{METODE PENELITIAN}

Penelitian ini merupakan penelitian deskriptif, dengan tujuan untuk mendeskripsikan hasil observasi/pengamatan akivitas mahasiswa dan dosen. Subjek dalam penelitian ini adalah mahasiswa semester IV kelas C Program Studi Pendidikan Matematika Universitas Cokroaminoto Palopo semester genap tahun akademik 2016/2017 sebanyak 40 orang. Teknik yang digunakan dalam pengumpulan data pada penelitian ini adalah metode observasi. Metode observasi digunakan untuk mengetahui aktivitas mahasiswa pada kegiatan Plan, Do, dan See. Instrumen yang digunakan adalah lembar observasi/pengamatan aktivitas mahasiswa pada kegiatan "Do" untuk mengetahui kualitas pembelajaran mata kuliah Program Linear.

Pelaksanaan Lesson Study sesuai dengan penelitian yang telah dilakukan oleh Pang (Mulayatun, 2017) meliputi tiga tahapan yaitu plan, do, see. Rincian dari tahapan ini adalah (a) Plan yaitu melakukan perencanaan secara kolaboratif antara mahasiswa calon guru, guru pamong, dan dosen pembimbing lapangan, (b) Do, melaksanakan pembelajaran sesuai dengan perencanaan yang sudah dilakukan dengan diamati oleh observer, dan (c) See melakukan refleksi hasil pelaksanaan pembelajaran $(D o)$ berdasarkan hasil observasi.

\section{HASIL PENELITIAN DAN PEMBAHASAN}

Pada bagian ini akan dijelaskan gambaran pelaksanaan pembelajaran pada mata kuliah program linear yang terdiri dari dua siklus. Setiap siklus terdiri atas penjelasan tentang kegiatan perencanaan (plan), pelaksanaan (do), dan refleksi (see). Hasil pelaksanaan lesson study pada setiap siklus dipaparkan sebagai berikut:

\section{Tahap perencanaan (Plan)}

Implementasi Lesson Study yang dilakukan oleh IMSTEP-JICA di Indonesia, Saito dkk, (Suardi, 2016) pada tahap plan yaitu merencanakan pembelajaran dengan penggalian akademis pada topik dan alat-alat pembelajaran yang digunakan.

Tahap ini diawali dengan identifikasi permasalahan yang ada pada mahasiswa telah dilakukan sebelumnya oleh dosen pengampu. Selanjutnya pembuatan rencana pembelajaran yaitu Satuan Acara Perkuliahan (SAP), Lembar Kerja Mahasiswa (LKM), dan lembar observasi mahasiswa. Kemudian, perangkat pembelajaran yang telah disiapkan oleh dosen model didiskusikan dengan beberapa dosen lain yang bertindak sebagai observer untuk menghasilkan skenario pembelajaran agar tujuan pembelajaran 
dapat tercapai. Tujuan yang ingin dicapai pada tahap pelaksanaan pembelajaran adalah mahasiswa diharapkan dapat membuat model matematika dan menyelesaikan masalah maksimasi dengan menggunakan metode simpleks.

Hal ini sejalan dengan penelitian Suryaningtyas dkk. (2014) yang menuliskan bahwa dari hasil identifikasi masalah dan diskusi perencanaan pemecahannya, selanjutnya disusun dan dikemas dalam suatu perangkat yang terdiri atas: RPP, Petunjuk pelaksanaan pembelajaran, Lembar Kerja Mahasiswa (LKM), media atau alat peraga pembelajaran, instrumen penilaian proses dan hasil pembelajaran, dan lembar observasi pembelajaran.

Aspek yang didiskusikan pada tahap perencanaan meliputi beberapa hal yakni:

a. Model pembelajaran yang digunakan sebaiknya model pembelajaran kooperatif untuk memudahkan mahasiswa mendiskusikan permasalahan yang mereka dapatkan dalam LKM.

b. Setiap kelompok terdapat minimal 1 orang mahasiswa yang bertindak sebagai tutor yang dapat membantu dan mengarahkan teman-teman kelompoknya.

c. Memprediksikan waktu yang dibutuhkan mahasiswa untuk mengerjakan iterasi tiap masalah kemudian disesuaikan dengan alokasi waktu perkuliahan yaitu 100 menit setiap pertemuan.

d. LKM berisi masalah maksimasi dan tabel simpleks yang akan diisi oleh mahasiswa.

\section{Tahap Pelaksanaan (Do)}

Berdasrkan keiatan Lesson Study yang dilakukan oleh IMSTEP-JICA di Indonesia, Saito dkk, (Suardi, 2016) tahap do yaitu melaksanakan pembelajaran yang mengacu pada rencana pembelajaran dan alat-alat yang disediakan, serta mengundang teman-teman sejawat untuk mengamati.

Pada tahap ini dosen model bersama dengan dosen lain yang berperan sebagai observer melaksanakan perannya masing-masing. Dosen model melakukan pembelajaran sedangkan observer mencatat kegiatan yang diamati selama pembelajaran berlangsung. Kegiatan yang dilakukan oleh dosen model dan observer sejalan dengan penelitian yang dilakukan oleh Suryaningtyas dkk. (2014), dalam penelitiannya dijelaskan kegiatan pelaksanaan dan observasi, dosen model melakukan penyelenggaran 
belajar dan mengajar (PBM) dan observer beserta tim monev melakukan observasi dengan mencatat apa saja yang diamati saat proses pembelajaran berlangsung sesuai poin-poin yang tersedia dalam lembar observasi.

Pada awal pembelajaran, dosen model membagi mahasiswa ke dalam kelompok-kelompok kecil yang terdiri dari 4-5 mahasiswa. Selanjutnya, dosen model memberikan apersepsi kepada mahasiswa mengenai materi pada pertemuan sebelumnya dengan menanyakan langkah-langkah pemakaian metode simpleks, guna mengingatkan kembali mahasiswa tentang materi tersebut. Pada kegiatan inti, dosen model memberikan LKM tabel simpleks yang harus diselesaikan oleh setiap kelompok kemudian didiskusikan dengan anggota kelompok masing-masing. Dosen memberikan bantuan secara bertahap pada setiap kelompok yang tidak memahami jalan atau proses penyelesaian dari masalah yang diberikan. Setelah mahasiswa menyelesaikan LKM, kemudian setelah itu mahasiswa mempresentasikan hasil yang didapatkan untuk dibahas dalam diskusi kelas. Pada tahap terakhir, dosen model memberikan evaluasi pemahaman dengan memberikan pertanyaan yang terkait dengan materi yang telah dipelajari.

\section{Tahap Refleksi (See)}

Kegiatan Lesson Study yang dilakukan oleh IMSTEP-JICA di Indonesia, Saito dkk, (Suardi, 2016), tahap see yaitu melaksanakan refleksi melalui berbagai pendapat/tanggapan dan diskusi bersama pengamat/observer.

Tahap do yang telah dilaksanakan masih memiliki beberapa kendala dan kekurangan. Oleh karena itu, pada tahap ini dosen model dan observer melaksanakan diskusi mengenai hal yang perlu dibenahi pada proses perkuliahan antara lain:

a. Kerja kelompok tidak terealisasi, masih ada mahasiswa yang tidak terlibat dalam proses kerja kelompok. Pengaturan posisi duduk mahasiswa perlu dibenahi.

b. Beberapa mahasiswa mengerjakan LKM, dan yang lainnya tidak memperhatikan.

c. LKM seharusnya disesuaikan dengan jumlah mahasiswa.

d. Masih ada tutor yang tidak melaksanakan perannya.

Kegiatan yang dilakukan dosen model dan observer, sejalan dengan penelitian oleh Suryaningtyas dkk. (2014), dijelaskan bahwa setelah perkuliahan selesai maka dilakukan refleksi atas jalannya perkuliahan. 
Observer dan dosen model membahas kelebihan dan kekurangan yang terjadi selama perkuliahan berlangsung.

Berdasarkan hasil refleksi dari pembelajaran yang telah dilaksanakan maka diadakan kembali kegiatan plan untuk mengatasi hal-hal yang telah terjadi pada siklus pertama. Kegiatan yang dilaksanakan pada siklus kedua tidak jauh berbeda dengan pelaksanaan siklus pertama. Pelaksanaan kegiatan yang dilakukan pada siklus dua sebagai berikut:

\section{Tahap Perencanaan (Plan)}

Rencana tindakan pada pelaksanaan tahap kedua ini adalah hasil refleksi yang sudah dilakukan di akhir tahap pertama. Tujuan yang ingin dicapai pada tahap pelaksanaan pembelajaran adalah mahasiswa diharapkan dapat menyelesaikan masalah minimasi dengan menggunakan metode simpleks.

Aspek yang didiskusikan pada tahap perencanaan meliputi beberapa hal yakni:

a. Upaya dalam meningkatkan aktivitas mahasiswa pada kegiatan pembelajaran, dengan memberikan LKM pada setiap siswa tanpa membentuk kelompok terlebih dulu.

b. Setiap kelompok terdapat minimal 1 orang mahasiswa yang bertindak sebagai tutor yang dapat membantu dan mengarahkan teman-teman kelompoknya.

c. Memprediksikan waktu yang dibutuhkan mahasiswa untuk mengerjakan iterasi tiap masalah kemudian disesuaikan dengan alokasi waktu perkuliahan yaitu 100 menit setiap pertemuan. Setiap orang menyelesaikan masalah yang ada di LKM, kemudian membentuk kelompok.

d. Pada LKM diberikan tabel simpleks yang akan diiterasi, dan hasil iterasi LKM pada bagian pertama berada pada LKM bagian ke dua sampai pada LKM ke tiga yang dirancang untuk menemukan penyelesaian dari masalah program linear.

e. Berdasarkan bentuk LKM maka penyelesaian setiap masalah harus disatukan dari tiga kelompok sehingga bukan hanya kelompok kecil namun akan dibentuk kelompok besar dari gabungan 3 kelompok kecil sesuai dengan kode yang ada di LKM.

f. Penyusunan kelompok yang memiliki soal dengan kode yang sama sebaiknya berdekatan agar tidak susah dalam membentuk kelompok 


\section{Tahap Pelaksanaan (Do)}

Pada awal pembelajaran, dosen mengarahkan mahasiswa untuk duduk terpisah. Selanjutnya, dosen memberikan apersepsi kepada mahasiswa mengenai materi pada pertemuan sebelumnya dengan menanyakan langkah-langkah pemakaian metode simpleks untuk masalah maksimasi, guna mengingatkan kembali mahasiswa tentang materi tersebut. Pada kegiatan inti, dosen model memberikan LKM tabel simpleks yang harus diiterasi oleh setiap mahasiswa untuk dikerjakan secara mandiri terlebih dahulu kemudian bergabung dengan kelompok masingmasing untuk mendiskusikan jawaban dari LKM yang telah dikerjakan. Dosen memberikan bantuan secara bertahap pada setiap kelompok yang tidak memahami jalan atau proses penyelesaian dari masalah yang diberikan. Setelah mahasiswa menyelesaikan LKM, kemudian mahasiswa bergabung membentuk tiga kelompok besar, dalam hal ini setiap kelompok besar terdiri dari tiga kelompok kecil. Setelah itu mahasiswa mempresentasikan hasil yang didapatkan pada kelompok besar untuk dibahas dalam diskusi kelas. Pada tahap terakhir, dosen model memberikan evaluasi pemahaman dengan memberikan pertanyaan yang terkait dengan materi yang telah dipelajari. Kemudian meminta mahasiswa menyimpulkan perbedaan masalah maksimasi dan minimasi.

\section{Tahap Refleksi (See)}

Tahap do yang telah dilaksanakan masih memiliki beberapa kendala dan kekurangan. Oleh karena itu, pada tahap ini dosen model dan observer melaksanakan diskusi mengenai hal yang perlu dibenahi pada proses perkuliahan antara lain:

a. Pengaturan tempat duduk pada saat kerja mandiri dan kelompok agar tidak terlalu berjauhan untuk mengefisienkan waktu.

Kendala yang dihadapi dan upaya yang dilakukan

Dalam kegiatan pembelajaran ditemukan kendala-kendala:

1. Pemahaman materi prasyarat dan langkah-langkah pemakaian metode simpleks yang kurang, menyebabkan kemampuan menyelesaikan masalah pemrograman linear cenderung terhambat.

2. Materi ajar yang membutuhkan ketelitian dalam perhitungan sehingga membuat mahasiswa kurang termotivasi untuk mengkaji lebih jauh materi ini. 
3. Mahasiswa cenderung menunggu jawaban salah satu teman kelompoknya pada saat kerja mandiri.

Upaya yang dilakukan:

1. Merefisi pembelajaran dengan mengaitkan materi sebelumnya.

2. Memberi motivasi mahasiswa terkait pentingnya materi ini untuk menguasai materi selanjutnya.

3. Memberi arahan kepada mahasiswa untuk menyelesaikan masalah sebelum bergabung membentuk kelompok besar.

Menurut Lewis (Purwati \& Supandi, 2011) Lesson Study memungkinkan guru mengkaji secara cermat cara dan proses belajar serta tingkah laku siswa. Fokus Lesson Study hendaknya diarahkan pada peningkatan pembelajaran melalui pengamatan terhadap aktivitas belajar siswa.

Aktivitas mahasiswa yang diamati dalam proses pembelajaran yang dituangkan dalam lembar observasi aktivitas yang kemudian diisi oleh observer. Aktivitas mahasiswa selama pembelajaran dapat dilihat dari enam indikator yaitu (a) Antusias mahasiswa dalam mengikuti pelajaran, (b) Interaksi Mahasiswa dengan dosen, (c) Interaksi antar mahasiswa, (d) Kerjasama Kelompok, (e) Aktivitas mahasiswa dalam kelompok, dan (f) Partisipasi mahasiswa dalam menyimpulkan hasil pembahasan (Khasanah \& Fitriani, 2016). Data hasil observasi mahasiswa pada siklus I dan siklus II akan di sajikan dalam tabel berikut ini.

Tabel 1. Rata-Rata Hasil Observasi Mahasiswa pada Siklus I dan Siklus II

\begin{tabular}{clccc}
\hline No. & \multicolumn{1}{c}{ Indikator } & Siklus I & Siklus II \\
\hline 1 & $\begin{array}{l}\text { Antusias } \\
\text { mengikuti perkuliahan }\end{array}$ & mahasiswa & dalam & 3.6 \\
\hline 2 & $\begin{array}{l}\text { Interaksi Mahasiswa } \\
\text { dosen }\end{array}$ & dengan & 3.2 & 3.5 \\
\hline 3 & Interaksi antar mahasiswa & 3.6 & 3.8 \\
\hline 4 & Kerjasama Kelompok & 3.3 & 3.5 \\
\hline 5 & $\begin{array}{l}\text { Aktivitas mahasiswa dalam } \\
\text { kelompok }\end{array}$ & 3.5 & 3.8 \\
\hline 6 & $\begin{array}{l}\text { Partisipasi mahasiswa dalam } \\
\text { menyimpulkan hasil pembahasan }\end{array}$ & 2.9 & 3.6 \\
\hline & Rata-Rata & 3.3 & Sangat Aktif \\
\hline
\end{tabular}


Berdasarkan data di tabel 1 diperoleh rata-rata hasil aktivitas mahasiswa pada kegiatan lesson study siklus I yaitu 3.3, berdasarkan kriteria aktivitas yang dimodifikasi dari Ilyas dan Fitriani (2014) $(2.5 \leq \bar{x}<3.5)$ yang artinya mahasiswa aktif dalam kegiatan pembelajaran. Sedangkan pada kegiatan siklus II rata-rata aktivitas mahasiswa yaitu 3.6 berdasarkan kriteria aktivitas $(3.5 \leq \bar{x} \leq 4.0)$ berarti mahasiswa sangat aktif. Hasil observasi aktivitas mahasiswa pada kedua siklus mengalami peningkatan. Hasil ini sejalan dengan temuan Khasanah dan Fitriani (2016) yang menyatakan bahwa serangkaian kegiatan lesson study telah dapat meningkatkan keaktifan belajar mahasiswa. Winarsih dan Mulyani (2012) dalam penelitiannya telah berhasil meningkatkan profesionalisme guru IPA SMP Negeri 30 Semarang, mengembangkan perangkat pembelajaran, meningkatkan hasil belajar siswa, meningkatkan aktivitas siswa.

Peningkatan kualitas proses pembelajaran, ini dapat dilihat dari semakin banyaknya mahasiswa yang aktif. Hal ini juga ditandai dengan meningkatnya aktivitas mahasiswa yakni antusias mahasiswa dalam mengikuti pembelajaran, interaksi antar mahasiswa dan dosen, interaksi antara mahasiswa, kerja sama kelompok, aktivitas mahasiswa dalam kelompok, serta partisipasi mahasiswa dalam menyimpulkan hasil pembelajaran. Perkuliahan tidak lagi membosankan dan mahasiswa juga termotivasi dalam belajar mata kuliah program linear. Selain itu dosen model mendapat kesempatan untuk berkolaborasi dengan teman sejawat dalam memperbaiki kualitas pembelajaran.

Berdasarkan catatan observer yang disampaikan pada saat refleksi (see) bahwa mahasiswa mampu menjelaskan pekerjaannya kepada teman kelompok bahkan pada saat mempresentasikan hasil diskusinya, mahasiswa juga menyampaikan pendapat apabila ada yang keliru dalam proses diskusi kelompok, selain itu mahasiswa juga dapat menyimpulkan hasil pembelajaran. Dengan demikian dapat disimpulkan bahwa pemahaman mahasiswa dalam mengerjakan masalah maksimasi dengan metode simpleks telah meningkat.

\section{SIMPULAN}

Kesimpulan dari penelitian ini adalah dengan kegiatan lesson study dapat meningkatkan aktivitas mahasiswa dengan penerapan model kooperatif pada mata kuliah program linear, meningkatkan pemahaman mahasiswa dalam mengerjakan masalah maksimasi dengan metode simpleks, interaksi antar mahasiswa dalam pembelajaran meningkat. Dengan demikian model pembelajaran kooperatif pada mata kuliah program linear dalam kegiatan lesson 
study dapat memperbaiki proses dan kualitas pembelajaran. Penelitian ini mempunyai kelebihan yakni terciptanya pembelajaran yang kolaboratif dalam merencanakan pembelajaran, melaksanakan pembelajaran, dan mengevaluasi pembelajaran. Selain itu, memberi kesepakatan pada dosen untuk meneliti proses belajar serta pemahaman mahasiswa secara cermat dengan adanya beberapa observer. Namun, kegiatan ini memiliki kekurangan yaitu sulit mempertemukan para observer di waktu yang bersamaan. Implementasi lesson study secara berkelanjutan akan mempercepat peningkatan profesionalisme dosen dalam perkuliahan, yang diikuti oleh peningkatan kegiatan pembelajaran secara efektif.

\section{DAFTAR PUSTAKA}

Ibrahim, M. (2005). Pembelajaran kooperatif. Surabaya: Pusat Sains dan Matematika Sekolah Universitas Negeri Surabaya.

Ilyas, M., \& Fitriani, A. (2014). Pembelajaran matematika melalui model kooperatif tipe make a match dan tipe scrambel pada siswa kelas VII SMP Negeri 4 Palopo. Jurnal Sainsmat, 3(1), 62-75. Retrieved from http:/ / ojs.unm.ac.id/sainsmat/article/view/1015/259

Khasanah, U., \& Fitriani, H. (2016). Peningkatan aktivitas belajar mahasiswa melalui pembelajaran kooperatif tipe STAD dikolaborasikan dengan gallery work. Muhammadiyah University Press. Retrieved from https:// publikasiilmiah.ums.ac.id/xmlui/ bitstream/handle/11617/76 40/16.pdf?sequence $=1 \&$ isAllowed $=y$

Lewis, C. C. (2002). Lesson study: A handbook of teacher-led instructional change. Philadelphia, PA: Research for Better Schools, Inc.

Mulayatun. (2017). Lesson study: strategi alternatif peningkatan kompetensi calon guru kimia. Jurnal Inovasi Pendidikan, 11(1), 1816-1827. Retrieved from https://journal.unnes.ac.id/nju/index.php/JIPK/article/view/9709

Purwati, H., \& Supandi. (2011). Meningkatkan kompetensi dan profesionalisme dosen melalui lesson study. AKSIOMA : Jurnal Matematika Dan Pendidikan Matematika, 2(2). Retrieved from http://journal.upgris.ac.id/index.php/aksioma/article/view/42/38

Slavin, R. E. (2005). Cooperative learning: Theory, research, and practice (2nd ed.). Massachusetts: Allyn and Bacon. 
Suardi. (2016). Aktifitas mahasiswa dalam lesson study pada pmbelajaran english learning media. Prosiding Seminar Nasional, 2(1), 587-598. Retrieved from https://journal.uncp.ac.id/index.php/proceding/article/view/648/55 6

Suryaningtyas, W., Suprapti, E., Solikin, A., \& Shoffa, S. (2014). Implementasi lesson study berbasis karakter pada mata kuliah statistika dasar dengan menggunakan media gabuz. Didaktis, 14(1), 45-65.

Tadanugi, F. A. (2015). Efektivitas lesson study dalam pembelajaran matamatika. Jurnal KIP, 4(2), 887-894. Retrieved from http://journals.ukitoraja.ac.id/index.php/jkip/article/download/60/ $15 /$

Winarsih, A., \& Mulyani, S. (2012). Peningkatan profesionalisme guru IPA melalui lesson study dalam pengembangan model pembelajaran PBI. Jurnal Pendidikan IPA Indonesia, 1(1), 43-50. Retrieved from https://journal.unnes.ac.id/nju/index.php/jpii/article/view/2012 